\title{
Estudo Epidemiológico dos Coletores de Lixo Seletivo
}

Marcelo Haertel Miglioransa'

Letícia Cunha da Rosa'

Christiano Perin ${ }^{2}$

Gabriel Zatti Ramos²

Gilberto Ferreira Fossati ${ }^{3}$

Airton Stein ${ }^{4}$

\author{
Epidemiologic Study of the \\ Selective Garbage Collectors
}

'Acadêmicos de medicina da FFFCMPA. Monitores da Disciplina de Medicina Preventiva

'Doutorandos da FFFCMPA ${ }^{3}$ Professor Adjunto do Departamento de Medicina Preventiva da FFFCMPA. Coordenador dos Cursos de Especialização em Medicina do Trabalho e em Higiene Ocupacional da FFFCMPA.

${ }^{4}$ Professor Adjunto do Departamento de Medicina Preventiva da FFFCMPA
O artigo aborda epidemiologicamente o perfil dos coletores de lixo seletivo e descreve as lesões musculares e acidentes de trabalho mais freqüentes. Este estudo transversal foi desenvolvido com duas empresas (denominadas como empresa A e empresa B), em Porto Alegre, selecionando-se 50 funcionários aleatoriamente (presentes e aptos nos dias das entrevistas para a pesquisa) e aos quais foi aplicado um questionário. A Média de idade da amostra foi de 34 e 22 anos para a empresa $A$ e B, respectivamente. Cerca de $66 \%$ dos funcionários da empresa $B$ trabalham a menos de 5 anos na companhia, ao passo que $95 \%$ dos funcionários da empresa $A$ trabalham há mais de 5 anos. O índice de lesões entre as duas empresas é alta $90 \%$ e $46,6 \%$ para empresas $A$ e B, respectivamente. Lesões são mais comuns nos membros inferiores, seguidas pelas lesões dos membros superiores e da coluna. Ambas as empresas apresentavam deficiência do uso de equipamentos de proteção, sendo estes praticamente ignorados pelos funcionários, embora de uso obrigatório. As avaliações médicas são realizadas esporadicamente, sem acompanhamento regular. Ambas as empresas apresentam altos índices de leões em geral, sendo as lesões de membros inferiores mais comuns. Também são altos os índices de cortes e outros pequenos ferimentos, provavelmente pelo não uso de equipamentos de proteção obrigatórios.

Palavras-chaves Coletores de Lixo, Coleta Seletiva de Lixo, Acidentes de Trabalho - EPI.

Study the epidemiological profile of selective garbage collectors and describe the major muscle lesions and work acidents. Material and techniques this was a transversal study comparing the employees of the two principal companies who collects selective garbaje at Porto Alegre city, symbolized in this study as company A and company B. We applied a questionnaire randomly for 50 workers of the two companies. The mean age was 34 and 22 years old for company $A$ and $B$ respectively. Around sixty six percente of worker at company $B$ have les than 5 years of experience at the job, comparing with the $95 \%$ of the employees of the company $A$ who have more than 5 years at the job. The lesions indices are high at the two companies, 90 and $46, \%$ for company $A$ and $B$, respectively. The most common injuries were in inferior limbs, followed by upper limbs and column. Both the companies lack the do use of protection equipament in their workers, despite the obrigatory use in the work legislation. Medical evaluations are not regular. Both companies have a elevated percentage on injuries at work in general, being inferior limbs the most common ones. They also presented elevated indices of cuts and other small bruises, probably because of the no use of the obrigatory protection equipament.

Keywords Garbage Collectors, Selective Garbage Collect, Protection Equipaments, Work injuries. 


\section{Introdução}

A importância da Coleta Seletiva de Lixo vem crescendo devido ao maior valor que as pessoas estão dando para o destino do lixo [18]. O aumento da produção de lixo seco (papel, plástico, vidro, latas, etc.) tornou necessário o recurso da reciclagem do mesmo, já que certos materiais levam de anos a séculos para serem degradados. O trabalho do coletor de lixo aliado ao trabalho da população, com o dever de separar e acondicionar corretamente o lixo, leva o lixo seguramente ao seu destino e facilita o trabalho dos catadores, que separam o lixo orgânico do seco, quando estiverem, eventualmente, misturados.

Entretanto, poucos têm a verdadeira idéia de como é realizado o trabalho dos coletores de lixo, bem como dos riscos e doenças a que são submetidos. $O$ contato freqüente com agentes nocivos à saúde torna o recolhimento do lixo um dos trabalhos mais arriscados e insalubres que existem [20;21]. Dentre os perigos de se manipular o lixo e os agravos à saúde que podem ocorrer aos coletores, destacam-se, desde comprometimentos respiratórios, afecções musculares, patologias de coluna, afecções cardiovasculares, perdas auditivas, tabagismo e alcoolismo, bem como os acidentes de trabalho durante a realização da coleta $[4 ; 6 ; 7 ; 8 ; 11 ; 12 ; 13 ; 14 ; 15 ; 16 ; 17 ; 18$; $19 ; 22 ; 23 ; 24 ; 25 ; 26 ; 27 ; 28 ; 29 ;]$.

Esses acidentes parecem estar relacionados a vários fatores, tais como acondicionamento inadequado do lixo pela população $[21 ; 23]$, realização inadequada da coleta pelos coletores, mão de obra desqualificada [12], excesso de peso a que são submetidos e uso inadequado dos Equipamentos de Proteção Individual (EPIs).

Em Porto Alegre, a Coleta Seletiva é realizada por duas empresas, a saber: pelo DMLU (Departamento Municipal de Limpeza Urbana) e pela COOTRAVIPA (Cooperativa dos Trabalhadores das Vilas de Porto Alegre).

Neste artigo são descritas as características sócio-epidemiológicas, bem como as lesões musculares e os acidentes de trabalho mais freqüentemente ocorridos nos dois serviços de coleta de lixo seletivo de Porto Alegre.

\section{Material e métodos}

Entrevistados 50 coletores de lixo da Cole- ta Seletiva de Lixo da cidade de Porto Alegre, sendo que 30 coletores eram empregados pela empresa $B$ e 20 pela empresa $A$, todos do sexo masculino. Os motoristas foram excluídos da entrevista, pois seu trabalho não tem maior relevância neste estudo. Os critérios de inclusão na pesquisa foram a concordância em participar do estudo e que estivessem aptos (lúcidos e não alcoolizados) a serem submetidos a entrevista nos dias determinados para a realização da coleta de dados.

As entrevistas foram realizadas pela manhã, antes dos coletores saírem para o trabalho, permitindo, assim, observar o local, as condições de trabalho, bem como a dinâmica do mesmo. As entrevistas foram individuais e feitas a partir de um questionário previamente elaborado e estruturado sobre o perfil do trabalhador, acidentes e lesões relacionadas ao trabalho e utilização de equipamentos de proteção individual (EPI), bem como informações sobre os dois tipos de serviço de coleta. Este instrumento de coleta de dados abrangeu questões de múltipla escotha e abertas.

O banco de dados foi montado no Epi lfo 6.0 e os dados foram analisados no SPSS 10.0 for Windows. A análise dos resultados foi realizada através de métodos estatísticos como o Qui-quadrado, Coeficiente de Yule e Teste de Significância, considerando-se um $p<0,05$.

\section{Resultados}

\section{1) Perfil do Trabalhador}

\section{Empresa A}

Os coletores têm uma média de idade de $35 \pm 1,5$ anos sendo que $95 \%$ deles trabalha na coleta seletiva há mais de 5 anos. Dos coletores, $85 \%$ está satisfeito com o trabalho que realiza e $85 \%$ deles têm tirado férias ultimamente. Recebem um salário em torno de $\mathrm{R} \$ 500,00$ incluído o pagamento do adicional de insalubridade, previsto na Consolidação das Leis do Trabalho.

Quanto ao estado civil, 65\% se declara solteiro, estando incluído nesta porcentagem os que não tem a união oficializada, mas vivem com uma companheira. Do total de co- 
letores $90 \%$ tem filhos, sendo que $44 \%$ tem 3 ou mais filhos e $38,5 \%$ tem 2 filhos. O nível de escolaridade é baixo: $90 \%$ têm o Ensino Fundamental (primeiro grau) incompleto e apenas 10\% completaram o Ensino Fundamental.

Os dados referentes à ingesta de bebidas alcoólicas não são plenamente confiáveis, pois apesar de $65 \%$ dos entrevistados afirmar consumir bebidas alcoólicas, 93,5\% destes disseram consumi-las apenas nos finais de semana. Sabe-se que tanto os índices de alcoolismo, como os de bebedores habituais dentre os coletores de lixo são altos [12], havendo casos de afastamento do trabalho e internação em clínicas para tratamento, considerando-o como doença de trabalho de acordo com llário, 1989. Quanto ao tabagismo, 55\% afirmou fumar.

\section{Empresa B}

Os coletores têm uma média de idade de $22 \pm 3$ anos. Destes, $7 \%$ trabalha na empresa há mais de 5 anos, $66 \%$ entre 1 e 5 anos e $27 \%$ há menos de 1 ano. Em relação ao grau de satisfação, 82,5\% estão contentes com o trabalho que realizam. Recebem um salário entre $R \$ 200,00$ e $R \$ 300,00$, não incluindo o adicional de insalubridade, na ocasião da coleta dos dados, ao qual fazem juz $[5 ; 12 ; 20]$. Em decorrência do baixo salário $79 \%$ dos trabalhadores da empresa $B$ não têm tirado férias ultimamente ao contrário dos trabalhadores do DMLU onde a maioria deles costuma tirar férias regularmente.

Quanto ao estado civil, $89 \%$ são solteiros ou não tem uma relação legalizada. Do total de coletores $43 \%$ tem filhos, sendo que $46 \%$ tem apenas 1 filho, 31\% tem 2 filhos e $23 \%$ tem 3 filhos ou mais. O nível de escolaridade também é baixo: 79,2\% não completaram o Ensino Fundamental e 13,2\% completaram, 6,6\% iniciaram o Ensino Médio, não chegando a finalizá-lo.

Em relação ao consumo de bebidas alcoólicas, 59,5\% declarou ser consumidor e destes, $93,5 \%$ bebem apenas nos finais de semana. A fidelidade dos dados é a mesma dos referentes aos coletores da empresa $A$. $O$ índice de tabagismo, assim como na empresa A, é alto, em torno de $40 \%$, dados que confirmam a casuística de outros autores $[4 ; 12]$.

A Tabela 1 mostra a distribuição dos coletores de lixo em faixas etárias de acordo com a empresa em que trabalham. Constata-se que os trabalhadores da empresa $B$ são mais jovens (74\% entre 16 e 24 anos) em comparação aos da empresa A (65\% entre 28 e 36 anos).

Tabela 1 Distribuição etária dos coletores de lixo.

\begin{tabular}{c|c|c|c|c}
\hline \multirow{2}{*}{ Faixa Etária } & \multicolumn{2}{|c|}{ B } & \multicolumn{2}{c}{ A } \\
\cline { 2 - 5 } & $\mathrm{n}^{\mathbf{0}}$ & $\%$ & $\mathrm{n}^{\mathbf{0}}$ & $\%$ \\
\hline $16+20$ anos & 9 & 29 & 0 & 0 \\
\hline $20+24$ anos & 14 & 45 & 0 & 0 \\
\hline $24+28$ anos & 5 & 17 & 0 & 0 \\
\hline $28+32$ anos & 1 & 5 & 7 & 35 \\
\hline $32+36$ anos & 1 & 5 & 6 & 30 \\
\hline $36+40$ anos & 0 & 0 & 3 & 15 \\
\hline $40+44$ anos & 0 & 0 & 3 & 15 \\
\hline $44+48$ anos & 0 & 0 & 1 & 5 \\
\hline Total & 30 & 100 & 20 & 100 \\
\hline Média \pm DP $($ anos $)$ & & $22 \pm 3$ & & $34 \pm 1,5$
\end{tabular}


Na Tabela 2 podemos ver que $95 \%$ dos coletores da empresa A trabalham na empresa há 5 ou mais anos em comparação com apenas $7 \%$ dos trabalhadores da empresa $B$.

Tabela 2 Distribuição dos coletores de lixo segundo o tempo de serviço.

\begin{tabular}{c|c|c|c|c}
\hline \multirow{2}{*}{ Eempo de Serviço } & \multicolumn{2}{|c|}{ B } & \multicolumn{2}{c}{ A } \\
\cline { 2 - 5 } & $\mathrm{n}^{\mathbf{0}}$ & $\%$ & $\mathrm{n}^{\mathbf{0}}$ & $\%$ \\
\hline $0+1$ anos & 8 & 27 & 0 & 0 \\
\hline $1+5$ anos & 20 & 66 & 1 & 5 \\
\hline$>5$ anos & 2 & 7 & 19 & 95 \\
\hline TOTAL & 30 & 100 & 20 & 100 \\
\hline
\end{tabular}

\section{Processo de trabalho e impacto na saúde do trabalhador}

O trabalho realizado pelos coletores das duas empresas é o mesmo, sendo que a divisão nos grupos por caminhão independe da empresa para a qual trabalham. Cada caminhão comporta 5 trabalhadores, incluindo o motorista, o qual tem a responsabilidade de controlar o andamento do serviço e resolver possíveis empecilhos que ocorrerem durante a coleta. Os coordenadores gerais da coleta seletiva esporadicamente acompanham-na, não havendo, assim, um rigor maior sobre o uso de EPIs pelos trabalhadores e realização adequada do trabalho.

A jornada de trabalho começa às 8 horas da manhã e se estende até o grupo completar a coleta dos bairros previamente determinados, podendo variar de 4 a 8 horas diárias. Não existe nenhum intervalo rígido para descanso e almoço durante o período de trabalho, podendo este ocorrer a critério dos trabalhadores. Entretanto, costuma ocorrer um intervalo para descanso durante o processo de descarregamento do caminhão. Às vezes, os próprios trabalhadores optam por não realizar o intervalo, para terminar o serviço mais cedo. Os coletores da empresa $A$ recebem da empresa um lanche neste intervalo, enquanto os da B não e muitas vezes contentam-se com as sobras dos colegas da empresa A.

O trabalho da coleta seletiva ocorre durante todos os dias da semana, exceto aos domingos, que constitui o dia de folga. $\mathrm{O}$ lixo é recolhido nas calçadas ou lixeiras e acondicionado em sacos plásticos de diversos tamanhos, sendo depositado na caçamba do caminhão coletor. No entanto, o conteúdo das lixeiras é bastante variado, encontrando-se desde caixas de papelão até móveis e utensílios domésticos.

Quanto à dinâmica do trabalho, os coletores costumam passar a maior parte do tempo correndo, subindo no caminhão apenas para descansar. Apesar desta rotina aparentemente desgastante, e do trabalho ser classificado como pesado [1], apenas $45 \%$ dos trabalhadores da empresa B e $47 \%$ da empresa $A$ afirmam sentirem cansaço durante a coleta e destes somente $55 \%$ da $\mathrm{A}$ e $64 \%$ da $B$ costumam descansar. Devido ao longo período de tempo que permanecem correndo - carregando pesos diferenciados o tempo todo- , a irregularidades do terreno, à pavimentação precária e ao constante movimento de subir e descer ruas [9], os acidentes de trabalho e as lesões são freqüentes: $25 \%$ da $A$ e $50 \%$ da B afirmam ter caído enquanto corriam para alcançar o caminhão (Tabela 3 e Gráfico 1). Torções no tornozelo são comuns. Dentre os lesionados, 33,3\% da A e $50 \%$ da B afirmaram já terem lesado o tornozelo (Tabela 4 e Gráfico 2). Os ligamentos são distendidos quando os tornozelos encontram-se em posição instável como ao correr, andar em solos instáveis e usar sapatos inadequados [3]. A maior proporção de quedas e torções dos trabalhadores da empresa B em relação aos da A é explicada devido ao menor tempo de senviço e inexperiência daqueles coletores, bem como pelo maior esforço que eles empreendem no trabalho. 
Tabela 3 Acidentes de trabalho ocorridos nos coletores de lixo.

\begin{tabular}{l|c|c|c|c}
\hline \multirow{2}{*}{ Ocorrência } & \multicolumn{2}{|c|}{ Empresa } & \multicolumn{2}{c}{ B } \\
\cline { 2 - 5 } & $\mathrm{n}^{\mathbf{0}}$ & $\%$ & $\mathrm{n}^{\mathbf{0}}$ & $\%$ \\
\hline Cortes & 19 & 95 & 26 & 86 \\
\hline Cair do Caminhão & 5 & 25 & 11 & 36 \\
\hline Cair durante a corrida & 5 & 25 & 15 & 50 \\
\hline Atropelamento & 0 & 0 & 2 & 7 \\
\hline
\end{tabular}

\section{$\square A \square B$}

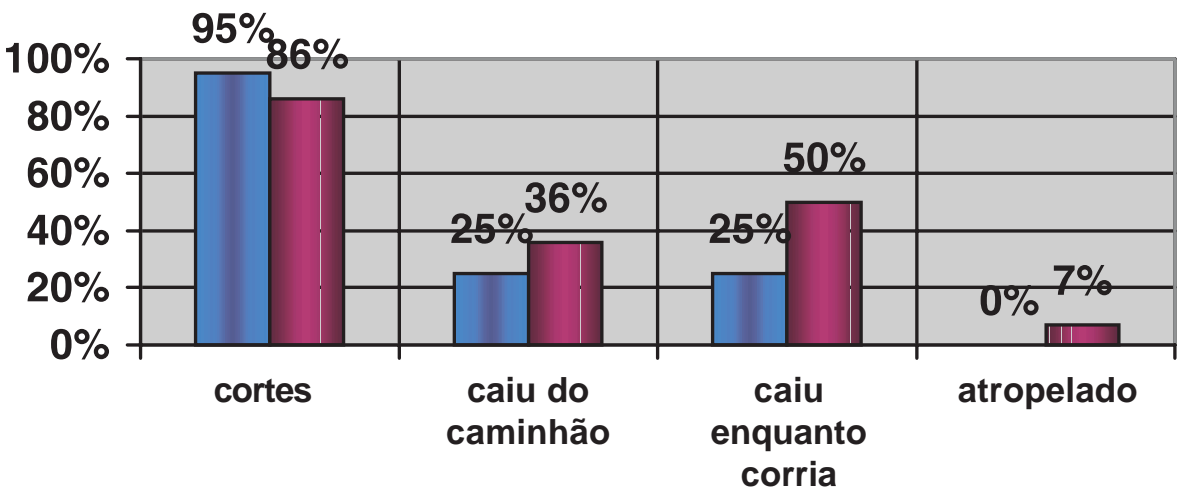

Tipo de acidente

Gráfico 1 Distribuição dos coletores de lixo segundo acidentes de trabalho.

Tabela 4 Segmentos corpóreos lesionados nos coletores de lixo.

\begin{tabular}{l|c|c|c|c}
\hline \multirow{2}{*}{ Segmento Corpóreo } & \multicolumn{2}{|c|}{ Empresa } & \multicolumn{2}{|c}{ B } \\
\cline { 2 - 5 } & $\mathrm{n}^{\circ}$ & $\%$ & $\mathrm{n}^{\circ}$ & $\%$ \\
\hline Tornozelo & 6 & 33,3 & 7 & 50 \\
\hline Joelho & 5 & 27,8 & 1 & 7,1 \\
\hline Coxa / Perna & 1 & 5,6 & 0 & 0,0 \\
\hline Virilha & 1 & 5,6 & 0 & 0,0 \\
\hline Coluna & 1 & 5,6 & 2 & 14,3 \\
\hline Ombro & 4 & 22,2 & 2 & 14,3 \\
\hline Braço / Antebraço & 0 & 0,0 & 2 & 14,3 \\
\hline TOTAL & 18 & 100 & 14 & 100 \\
\hline
\end{tabular}


A

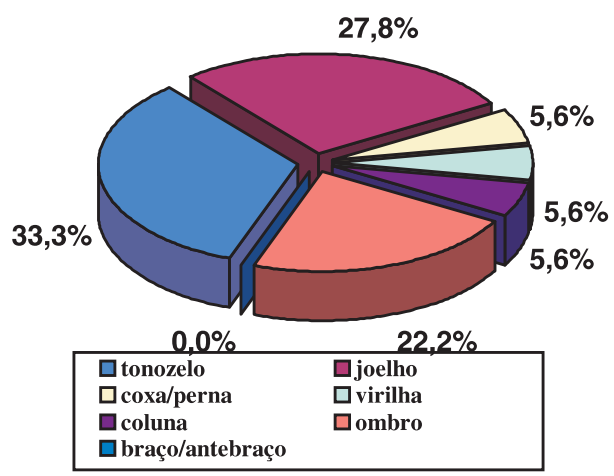

B

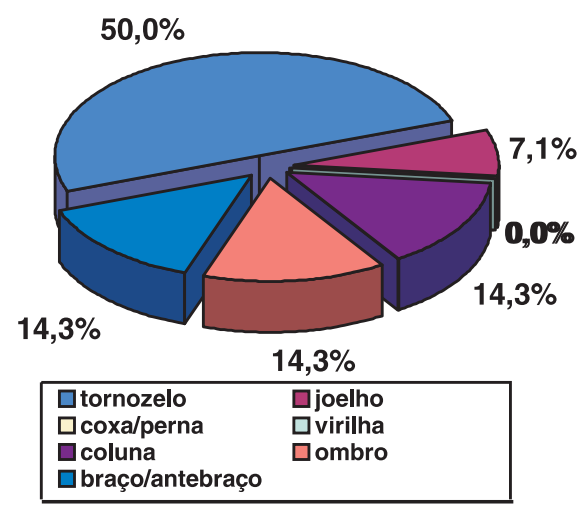

Gráfico 2 Segmentos corpóreos lesionados nos coletores de lixo de cada empresa.

Os trabalhadores costumam recolher e arremessar várias sacolas ao mesmo tempo. Como o lixo não é corretamente acondicionado pela população [21;23] e os trabalhadores não costumam usar luvas, queixandose de serem ruins e deixarem escorregar as sacolas; é freqüente a ocorrência de cortes e ferimentos por objetos pérfuro-cortantes: $95 \%$ da empresa $A$ e $80 \%$ da $B$ afirmam já terem se cortado. O processo de arremessar o lixo pode causar aparecimento de dor aguda no ombro, devido aos movimentos bruscos realizados, $15 \%$ da $\mathrm{A}$ e $10 \%$ da $\mathrm{B}$ apresentam dor. Quanto às lesões do ombro, elas aparecem com 22,2\% na empresa A e 14,3\% na $B$ das lesões sofridas. Apesar da prevalência de lesão ser maior nos trabalhadores da $A$, não foi encontrado significância estatística entre a maior média de idade dos trabalhadores da $\mathrm{A}$ e a sua maior prevalência de lesões no ombro. Contudo, a literatura mostra que lacerações da bainha músculo-tendínea são mais comuns em homens com uma média de idade maior, entre 40-50 anos [3]. Como os trabalhadores realizam ocupações manuais pesadas e movimentos não habituais, como o arremesso do lixo, a faixa de idade para lacerações é compensada pelo maior desgaste em virtude dos esforços físicos, o que justifica o alto índice de lesões do ombro tanto em trabalhadores da A como da B.

Devido aos horários de coleta coincidirem com os de tráfico intenso, o número de atropelamentos aumenta [26]. Assim, 6,67\% dos trabalhadores da empresa $B$ já foram atropelados.

Se dividirmos as lesões notificadas em grupos do membro superior, membro inferior e coluna, observa-se, em ambos serviços de coleta, uma maior prevalência de lesão dos membros inferiores, seguidos pelos membros superiores e coluna, casuística semelhante a de ROBAZZI 1992. (Tabela 5).

Tabela 5 Distribuição dos coletores de lixo quanto às lesões por área corporal.

\begin{tabular}{l|c|c|c|c}
\hline \multirow{2}{*}{ Lesão } & \multicolumn{2}{|c|}{ Empresa } & \multicolumn{2}{c}{ B } \\
\cline { 2 - 5 } & $\mathrm{n}^{\circ}$ & $\%$ & $\mathrm{n}^{\circ}$ & $\%$ \\
\hline Membros Superiores & 18 & 36 & 13 & 26 \\
\hline Membros Inferiores & 24 & 48 & 15 & 30 \\
\hline Coluna & 7 & 14 & 15 & 30 \\
\hline TOTAL & 17 & 100 & 14 & 100 \\
\hline
\end{tabular}

O maior aparecimento de lesões nos membros inferiores fica claro quando analisamos o ritmo de trabalho dos coletores. Como já citado, o exercício e esforço físico exigido no dinamismo do trabalho, faz dos membros inferiores um alvo de contusões e distensões. Colidir com o caminhão de lixo, roçar os sacos de lixo nas coxas e pernas, tropeçar e 
cair de mau jeito durante a corrida são ações que justificam a preponderância das lesões nos membros inferiores. Chama atenção, dentre o total de lesados, para a prevalência de $27,8 \%$ de lesões no joelho nos coletores a servico da empresa A para 7,1\% dos coletores da empresa B (Tabela 4 e Gráfico 2). Dados que ao serem analisados provam que existe significância e associaccão positiva entre a maior média de idade dos trabalhadores da $\mathrm{A}$ e o seu maior índice de lesões do joelho $(p<0,05)$. A idade avançada e o maior tempo de serviço proporcionam um maior desgaste da articulação do joelho, que, estando sujeita à sustentação de peso e intensas pressões, comumente apresenta sinais de destruição pelo uso e de osteoartrose.

As lesões dos membros superiores também se devem a realização incorreta do serviço, principalmente ao arremesso de sacolas pesadas, sendo a maior causa de dor no ombro. Não proteger as mãos adequadamente, pela não utilização das luvas, reflete no alto indice de cortes.

As lesões da coluna vertebral são compreendidas pela presença de objetos pesados (alguns coletores relataram ter carregado geladeiras e móveis), que induzem posturas inadequadas e esforço muscular. Lesões, refletindo em dor aguda na coluna, são mais freqüentemente encontradas em jovens em torno dos 25 anos [3], justificando o maior aparecimento destas lesões nos coletores da empresa B.

\section{Equipamentos de Proteção Individual}

Os equipamentos de proteção individual (EPIs) são descritos como qualquer dispositivo de uso individual, que e destinado a proteger a saúde e a integridade física do trabalhador. O uso destes equipamentos é obrigatório e deve ser exigido pela empresa, no entanto, foi observado neste estudo que há um descaso dos coordenadores quanto a essa exigência.

O trabalho dos coletores de lixo é classificado como insalubridade de grau máximo $[5 ; 12 ; 21]$, sendo importante a utilização dos EPIs na proteção do trabalhador, visando minimizar o índice de lesões e acidentes de trabalho. A escolha do EPI depende da atividade exercida pelo trabalhador, do local de trabalho, das condições ambientais e do tempo de exposição do trabalhador ao risco [2]. Pelo trabalho ser realizado a cév aberto torna-se obrigatório o uso de abrigos, para proteger contra intempéries. Também é exigido - uso de bonés ou similares para proteger contra a insolação excessiva, e capas de chuva para proteção contra chuva, frio e umidade (NR-21). A utilização de luvas é obrigatória devido ao contato constante com materiais e objetos escoriantes, cortantes ou perfurantes. Os calçados devem ser impermeáveis e oferecer proteção contra objetos, detritos e choques mecânicos [2].

Apesar das exigências, a utilização correta dos EPIs pelos trabalhadores não é executada: nenhum trabalhador da $A$ utiliza luvas e apenas $13,3 \%$ dos trabalhadores da $B$ as utilizam (Gráfico 3). Dos coletores, 26,6\% da $A$ e $33,3 \%$ da B utilizam boné (Gráfico 4). Todos os trabalhadores da $A$ e $93,3 \%$ da $B$ usam tênis, os demais utilizam sapatos de couro. Quanto ao uniforme, os coletores afirmam usar camiseta e bermuda da empresa, no entanto, a proteção dos membros superiores e inferiores seria mais adequada se fossem utilizados calça e jaleco. A baixa utilização das luvas é justificada pelos lixeiros por serem incômodas, escorregadias, de péssima qualidade e difícil manuseio, motivos semelhantes aos achados por ROBAZZI 1994. Outros fatores que podem justificar o baixo uso dos EPIs são os efeitos adversos por eles causados, tais como: dermatites de contato por sensibilização, dermatites irritativas por atrito, calosidades, micoses e desconforto [10].

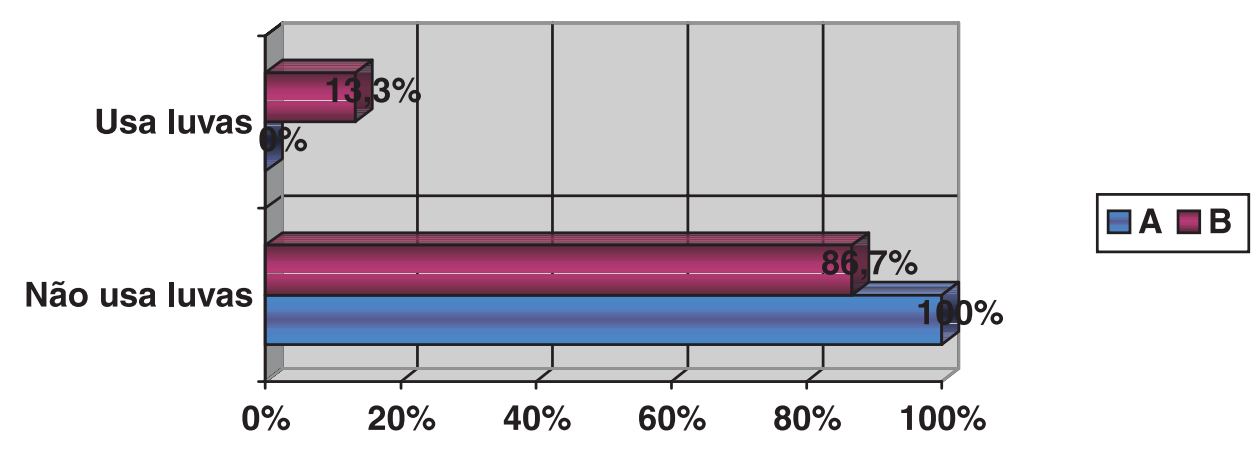

Gráfico 3 Utilização de luvas conforme a empresa. 


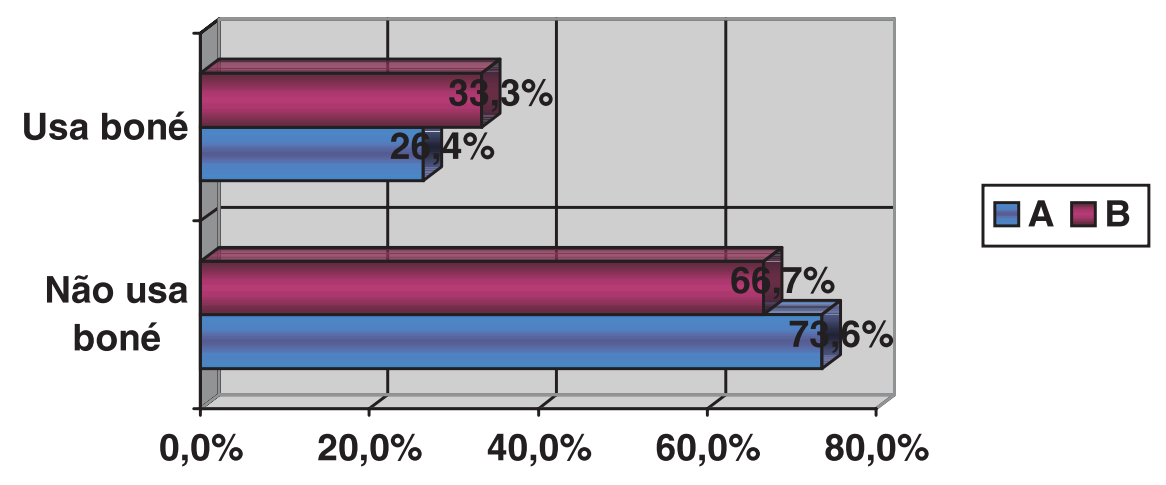

Gráfico 4 Utilização de boné conforme a empresa.

Embora seja obrigatório o fornecimento dos EPIs ao trabalhador pela empresa, foi constatado que a empresa $B$ desconta a aquisição dos mesmos do salário dos coletores. Os tênis utilizados pelos coletores são, na maioria retirados das lixeiras ou encontrados pelo chão, podendo estar em más condições, não protegendo adequadamente o trabalhador. Apesar de a empresa A fornecer os EPIs aos seus funcionários, as queixas de péssima qualidade e desconforto permanecem, fazendo com que os coletores da $A$ se utilizem dos mesmos meios que os da $B$ para adquirir os equipamentos.

É preciso ter em mente que o simples uso do EPI não significa que a proteção será alcançada. Realizar exames médicos periódicos e comparar os exames admissionais e demissionais são procedimentos indispensáveis para verificar a real proteção pretendida $[5 ; 12 ; 21]$. No entanto, exames médicos são realizados esporadicamente, como que uma vez ao ano. Os trabalhadores confessam não ser rotineira a visita ao serviço médico e poucos trabalhadores só o utilizam quando há aparecimento de dor forte $135 \%$ da empresa $A$ e $21,5 \%$ da B).

\section{Conclusão}

Existem diferenças entre os dois serviços de coleta. A empresa A proporciona maior estabilidade aos seus funcionários e melhores condições de trabalho, pois fornecem alimentação e piso salarial condizente com a importância do trabalho que executam, o que reflete no alto índice de satisfação apresentado.

A prevalência de lesões de ombro é alta tanto em trabalhadores da A como em trabalhadores da B, não existindo, entretanto, neste caso importância estatística entre a maior média de idade e maior tempo de serviço com o índice de lesões de ombro. Quanto às lesões de joelho, é maior a prevalência nos coletores da A, devido a maior média de idade e tempo de serviço prestado, resultados esses comprovados estatisticamente. $O$ impacto nesses segmentos é constante, devido às operações realizadas (corridas intensas e constantes, levantamento e arremesso de peso) que agravam as chances de ocorrerem lesões. No entanto, lesões do tornozelo e coluna são mais freqüentes nos coletores da empresa $B$, pois, como mencionado, problemas no tornozelo devem-se ao maior desgaste físico no trabalho e ao pouco conhecimento a seu respeito, devido ao menor tempo de serviço. As lesões da coluna vertebral justificam-se pela menor média de idade e levantamento de peso excessivo, realizado em posições inadequadas.

Os trabalhadores não têm o hábito de utilizar EPIs durante a realização de seu ofício. Se esses equipamentos fossem devidamente utilizados, diminuiriam o índice de cortes e lesões cutâneas, devido ao contato constante das sacolas com os membros expostos.

O empregador deveria dar mais atenção à saúde do trabalhador, fornecendo atendimento médico periódico e tentando conscientizálos da importância de procurar esse serviço quando necessário. Também deveria fornecer EPls de melhor qualidade e tornar obrigatória a utilização dos mesmos, melhorando assim a qualidade do serviço e preservando a saúde do trabalhador. 


\section{Referências bibliográficas}

1. ANJOS, L.A., Ferreira, J.A. A avaliação da Carga fisiológica de trabalho na legislação brasileira deve ser revista! $O$ caso da coleta de lixo domiciliar no Rio de Janeiro. Cad. Saúde Pública. 16(3): 785-790, 2000.

2. BENSOUSSAN, E. Manual de Higiene, Seguranca e Medicina do Trabalho, 1992.

3. CAILLIET,R. Síndromes Dolorosos. São Paulo: Manole, 1976.

4. CAMPANA, C.L. Tabagismo entre Periciados de Acidentes de TrabaIho. Revista Brasileira de Saúde Ocupacional, São Paulo, 13 (50):88-09, 1985.

5. CAMPANHOLE, A. \& CAMPANHOLE, H.L. Consolidação das Leis do Trabalho. $58^{\circ}$ ed. São Paulo, Ed. Atlas, 1982. $1085 p$.

6. CHAUMONT, A.J. et al. La Collete des Ordures et Dechets, ses Risques Professionels. Arch. Mal. Profession., 33(7/8): 429-34, 1975.

7. DUCEL, G. et al. Importance de I'exposicion bactérienne chez les employés de la voirie chargés de la levé et des ordures. Soz. Praventivimed, 21(4):136-8, 1976.

8. FARIA, M.P.; SILVA, A.M. Análise de acidentes do trabalho ocorridos durante parte do ano de 1983 na Grande Belo Horizonte (MG). Ver. Bras. Saúde Ocup. 53(14):26-32, 1986.

9. FERREIRA, J.A. Lixo Hospitalar e Domiciliar: Semelhanças e Diferenças. Estudo de Caso no Município do Rio de Janeiro. Tese de Doutorado, Rio de Janeiro: Escola Nacional de Saúde Pública, Fundação Oswaldo Cruz. 1997.

10. FERREIRA Jo, Y.M. A Atuação da Medicina do Trabalho em Face da Utilização dos Equipamentos de Proteção Individual. Revista Brasileira de Saúde Ocupacional. 50(13):75-6, 1985.

11. FORANTTINI, O. Aspectos Epidemiológicos Ligados ao Lixo. In: Universidade de São Paulo. Faculdade de Higiene e Saúde Pública. Lixo e Limpeza Pública. São Paulo, USP/OMS/OPS, 1969. Cap. 3 p.1-19.

12. ILÁRIO, E. Estudo de morbidade em coletores de lixo de um grande centro urbano. In: Revista Brasileira de Saúde Ocupacional, n.66, v.17, abril/junho, 1989.

13. IVENS, U.I., et al. Injuries Among Domestic Waste Collectos. Am J Ind Med. 33(2): 182-9, 1998.

14. KESSLER, M. et al. Área de ruídos em serviço público de limpeza doméstica. Zhe Arbeitsmed, v.17, p.34-9, 1987.

15. KENPER, H.C.G. et al. The Physical and Physiological workload of refuse collector. Ergonomics, 33(12):1471-86, 1990.

16. OLIVEIRA, W.E. Saneamento do Lixo. In: Universidade de São Paulo. Faculdade de Higiene e Saúde Pública. Lixo e Limpeza Pública. São Paulo, USP/OMS/ OPS, 1969. Cap. 1 p.1-18.

17. PACHECO, J.N. Considerações sobre os Processos de Disposição Final do Lixo; aspectos gerais que interessam à saúde pública. Arq. Hig. Saúde Públ. 26(89):199-216, 1961. 
18. POULSEN, O.M. et al. Collection of Domestic waste. Review of Occupational health problems and their possible causes. The Science of the Total Environment 170 (1995) 1-19.

19. POULSEN, O.M., et al. Sorting and recycling of domestic waste. Review of Occupational health problems and their possible causes. The Science of the Total Environment 168 (1995) 33-56.

20. ROBAZZI, M.L. Algumas considerações sobre o trabalho dos coletores de lixo. In: Revista Brasileira de Saúde Ocupacional, São Paulo, n.76, v.20, p.34-41, julho/dezembro, 1992.

21. ROBAZZI, M.L.C.C. Coletores de lixo: estudo de afastamentos do serviço por problemas de saúde. In: Revista Brasileira de Saúde Ocupacional, n.50, v.13, abril/junho, 1985.

22. ROBAZZI, M.L.C.C. Contribuição ao Estudo sobre coletores de lixo: acidentes de trabalho ocorridos em Ribeirão Preto, 1991. 185p. Tese de Doutorado. Escola de Enfermagem de Ribeirão Preto, Universidade de São Paulo.

23. ROBAZZI, M.L.C.C. et al. O serviço dos coletores de lixo: riscos ocupacionais versus agravos à saúde. In: Revista da Escola de Enfermagem da USP, n.2, v.28, p. 177-190, agosto, 1994.
24. SCHIBYE, B., et al. Aerobic Power and Muscle Strength Among Young and Elderly Workers with and without physically demanding work tasks. Appl Ergon. 32(5):425-31, 2001.

25. SILVA, E.P. Condições de Saúde Ocupacional dos Lixeiros de São Paulo. São Paulo, USP/ Faculdade de Saúde Pública, 1973. 89p. (Dissertação de Mestrado).

26. VELLOSO, M.P. Processo de trabalho e acidentes de trabalho em coletores de lixo domiciliar na cidade do Rio de Janeiro, Brasil. In: Caderno de Saúde Pública, n.4, v.13, outubro, 1997.

27. YANG, C.Y., et al. Adverse Health Effects Among Household Waste Collectors in Taiwan. Environ Res. 85(3):195-9, 2001.

28. WALSH, K. et al. Occupational causes of Low-back apin. S.J. Work Environ. Health. V. 15 p. 54-9, 1989.

29. WOUTERS, I.M., et al. Upper Airway Inflammation and Respiratory Symptoms in Domestic Waste Collectors. Occup Environ Med 59(2):106-12. 2002.

30. ABPA. Acidentes do trabalho e estatísticas. In: Associação Brasileira para Prevenção de Acidentes, n.4, v.21, 1986. 